\title{
O LUGAR DE ENCONTRO NAS PRAÇAS PÚBLICAS DO DISTRITO FEDERAL: AS INTERVENÇÕES ARTÍSTICAS PELOS AFETOS
}

\author{
Lorena da Silva Figueiredo ${ }^{1}$ \\ Gabriela Pereira de Freitas ${ }^{2}$
}

\section{Introdução}

Desde os primórdios da Antiguidade Clássica, as praças surgiram como um espaço público para apresentação do poder soberano à população. A partir do século XVII, com o desenvolvimento mercantil e a expansão das cidades, este espaço urbano passou a se estruturar principalmente em regiões centrais e próximo às instituições de poder, como os órgãos estatais e a Igreja. Tendo em vista, mais recentemente, o processo de urbanização pautado pelos conceitos modernistas, as cidades brasileiras foram influenciadas pelos ideais europeus e seus desdobramentos econômicos e políticos, passando a contar com construções arquitetônicas do gênero, nos século XIX e início do século XX. Por meio desta circulação de ideias, a paisagem urbana nacional se modificou intensamente com a abertura de ruas e a criação de áreas grandes para o fluxo de pedestres e meios de transporte.

Nesta perspectiva de desvelamento entre os processos históricos e sociais associados à criação das praças pelo processo de urbanização das cidades, observamos uma lógica complexa imposta pelos padrões de construções arquitetônicas e a produção do espaço que vai além da estrutura visível. O pesquisador Lauande Junior (2008) nos apresenta um conceito sobre a praça que propicia pensarmos neste lugar como dispositivo: "a praça deve ser entendida, como qualquer categoria do espaço urbano: o resultado da interação de vários aspectos que emprestam características próprias a um determinado sistema social temporal, que a produz". (Lauande Junior, 2008: 47). Assim sendo, as relações entre o espaço da praça se expandem no âmbito do espaço público e incorporam significados e afetos em sua estrutura de formação.

\footnotetext{
${ }^{1}$ Universidade de Brasília, Brasil. Email: lorena5.figueiredo@gmail.com. ORCID id: https://orcid.org/0000-0002-5735-2440

2 Universidade de Brasília, Brasil Email: gabriela.freitas@gmail.com ORCID id: https://orcid.org/0000-0002-6195-3871
} 
Ao pensarmos a praça como um dispositivo que se associa neste jogo entre poderes, em especial propiciados pela urbanização das cidades, uma rede é composta pelo entrelaçamento presente nas construções, nas ruas, nas pessoas e nas instituições, gerando uma imagem deste lugar. Vale ressaltar que "o poder não tem essência, ele é operatório. Não é atributo, mas relação de poder é o conjunto de relações de forças, que passa tanto pelas forças dominadas quanto pelas dominantes, ambas constituindo singularidades. (Deleuze, 2005: 37). Neste diálogo, a imagem da cidade se associa aos encontros entre os poderes que a atravessam, potencializando novas singularidades de operar no espaço urbano por meio da Estética. Portanto, as alianças entre os conceitos e os processos de urbanização se articulam neste sistema aberto por rizomas ${ }^{3}$ e permitem a problematização deste corpo ao comporem uma cartografia social entre as praças da região do Plano Piloto e das Cidades-Satélites, como é a proposta deste artigo.

\section{A cartografia presente no lugar de encontro das praças}

Consideramos a praça um corpo que é afetado por múltiplas relações (sociais, econômicas e políticas) em sua formação. Delimitar uma construção em espaço público e estabelecer algo novo ao tecido urbano nos permite uma tomada de consciência para lembrarmos que este ambiente pertence à população e não se restringe à esfera privada. A partir desta configuração, o conceito de corpo proposto pela filosofia de Spinoza nos ajuda a buscar a compreensão do lugar de encontro proporcionado pela atuação deste espaço público em decorrência das interações entre as pessoas e o espaço urbano.

O objeto da ideia que constitui a mente humana é o corpo, e o corpo existente em ato. Ademais, como não existe nada de que não se siga algum efeito, se, além do corpo, existisse ainda outro objeto da mente, deveria necessariamente existir em nossa mente a ideia desse efeito. Logo, o objeto da nossa mente é o corpo existente. (Spinoza, 2009: 61)

O processo de urbanização é, portanto, também resultado da mente humana em ato e opera na vida real. Sendo assim, as praças podem ser compreendidas como produtos desta extensão da mente humana, tornando-se um corpo existente. A importância do evento é crucial para que a compreendamos no espaço público e fundamentemos a reflexão proposta. Ao pensarmos no evento como acontecimento, de acordo com a

\footnotetext{
3 O conceito de Rizoma é criado pelos autores Deleuze e Guattari designada propor uma estrutura semelhante a um caule nesta troca entre ideias, saberes e poderes constantemente. É importante compreender que "um rizoma não começa nem conclui, ele se encontra sempre no meio, entre as coisas, intermezzo. A árvore é filiação, mas o rizoma é aliança”. (Deleuze \& Guattari, 1995: 7)
} 
filosofia spinozista, estabelecemos a capacidade de termos um corpo afetado, ou seja, de sua potência de agir variável por uma afecção. Neste sentido temos uma definição que estabelece essa relação: "por afeto compreendo as afecções do corpo, pelas quais sua potência de agir é aumentada ou diminuída, estimulada ou refreada, e, ao mesmo tempo, as ideias dessas afecções”. (Spinoza, 2009: 98). Desse modo, os afetos se constituem através deste intervalo entre tempo e espaço, ocasionando a possibilidade de acontecer o encontro por meio dessas afecções que atravessam o corpo, tal como acreditamos se desenrolar nas praças urbanas.

Para a autora Raquel Rolnik, a natureza das cidades propicia essa organização social que se desenvolve pela rede de relações presente no dispositivo de poderes, e “imbricada, portanto, com a natureza mesma da cidade está a organização da vida social e consequentemente a necessidade de gestão coletiva. Indissociável à existência material da cidade está sua existência política.” (Rolnik, 2017: 4).

Por meio dos afetos, percebemos as práticas políticas determinadas ao uso coletivo do espaço urbano em constante transformação. No entanto, as mudanças estabelecidas pelos processos econômicos e políticos em decorrência da implantação do modelo de gestão Neoliberal geraram uma intensidade de variações no comportamento das cidades e fraturas profundas, em especial no Brasil, a partir dos anos de 1990, o que não foi diferente em relação às praças públicas, cujo valor do espaço privado entra em voga em prol do uso do território nesta dialética entre global e local.

\begin{abstract}
A corporatização do território, com a destinação prioritária de recursos para atender as necessidades geográficas das grandes empresas, acaba por afetar toda a sociedade, já que a despesa pública ganha um perfil largamente desfavorável à solução de problemas sociais e locais. O orçamento é uma norma que, nesse caso, resolvendo um aspecto do conflito distributivo, em favor da economia globalizada, agrava outros. Mas o orçamento não é global, mas nacional, territorializado. (Santos, 2006: 229)
\end{abstract}

Aos poucos, o Neoliberalismo se afirma como um sistema de intervenção na sociedade em geral para promoção da circulação de mercadorias na economia através de uma rede de poderes, tendo o processo de urbanização nas cidades como um dos pilares para sua organização. É importante compreendermos o contexto histórico brasileiro anterior para situarmos as ações apresentadas por este sistema ao momento presente. $\mathrm{O}$ Brasil passou por um longo período antidemocrático que gerou uma recessão econômica durante décadas marcado pela Ditadura Militar (1964-1985). 
Após a abertura do regime político, as conjunturas internacionais se desenvolveram a partir dos preceitos da globalização ${ }^{4}$ e tomaram como alicerce o modo de gestão neoliberal para fundamentar um discurso de retomada econômica e promoção do desenvolvimento. O pesquisador Adilson Marques Gennari, no texto "Globalização, Neoliberalismo e Abertura Econômica do Brasil nos anos 90", apresenta uma reflexão sobre as estratégias adotadas pelo Estado brasileiro, que são influenciadas pela privatização dos espaços e a falta de interesse do uso do espaço público pela gestão do Estado, criando vários embates pelas cidades contemporâneas.

A perda de autonomia e de poder decisório por parte do Estado Nacional é uma opção política e não uma derivação mecânica e irredutível das mudanças nas estruturas do modo de produção capitalista em seu processo de globalização. No fundo, as ações do Estado se ampliam, mas obviamente no sentido da regulação para a transferência do fundo público em proporção crescente para o financiamento do setor privado, vis a vis à reprodução de força de trabalho. (Gennari, 2002: 42-43)

A partir desta configuração, observamos uma inversão do uso dos espaços públicos em detrimento do uso privado que atravessa o comportamento das praças. Os autores Dardot e Laval, na obra A nova Razão do mundo, nos apresentam o conceito de racionalidade neoliberal implementada por este sistema econômico e suas formas de organização discursiva e operante na sociedade.

A racionalidade neoliberal tem como característica principal a generalização da concorrência como norma de conduta e da empresa como modelo de subjetivação. $\mathrm{O}$ termo racionalidade não é empregado aqui como um eufemismo que nos permite evitar a palavra "capitalismo". O neoliberalismo é a razão do capitalismo contemporâneo, de um capitalismo desimpedido de suas referências arcaizantes e plenamente assumido como construção histórica e norma geral de vida. (Dardot e Laval, 2016: 14)

No caso brasileiro, em especial em Brasília, percebemos um abandono dos espaços públicos das praças e a mudança da paisagem urbana na região do Plano Piloto. Ocorre um deslocamento do uso destes espaços para as áreas internas de shopping centers. Com relação à região localizada nas cidades-satélites, a praça atua de uma maneira singular, como refletiremos mais adiante, mas sendo afetada, também, por esse movimento centrífugo do uso dos espaços externos em decorrência dos espaços internos.

\footnotetext{
${ }^{4}$ Para o autor Milton Santos, a globalização se constitui em um caráter perverso atual à humanidade. "A emergência do dinheiro em estado puro como motor da vida econômica e social. São duas violências centrais, alicerces do sistema ideológico que justifica as ações hegemônicas e leva ao império das fabulações, a percepções fragmentadas e ao discurso único de mundo". (Santos, 2006: 19). Hoje, vemos essa perversidade associada ao neoliberalismo e à invisibilidade de poderes inerentes a este modo de gestão econômica implantada.
} 
Sendo assim, o não-pertencimento associado ao medo compõe novos afetos derivados do abandono destes espaços em virtude da ausência de investimento Estatal e das práticas discursivas associadas a este modo de gestão neoliberal. A imagem da praça se constitui em uma nova paisagem urbana cujo sucateamento, o esvaziamento e o apagamento da memória materializam uma nova concepção do imaginário urbano em construção e dos hábitos de se compartilhar neste espaço. Segundo Ferrara, "a paisagem corresponde a uma forma visual da materialidade urbana, mas construída pelo imaginário que se amplia em múltiplos contornos". (Ferrara, 2012: 47). Desta forma, a gênese que alia a filosofia spinozista ao lugar de encontro se torna incapacitada de promover o evento nas praças e daí emergem transformações paisagísticas que produzem espaços outros por meio das subjetividades.

Cada vez que a sociedade passa por um processo de mudança, a economia, as relações sociais e políticas também mudam, em ritmos e intensidades variados. A mesma coisa acontece em relação ao espaço e à paisagem que se transformam para se adaptar às novas necessidades da sociedade. (Santos, 1997: 37)

A lógica apresentada pelo discurso neoliberal se fundamentou em compor uma ideia que o espaço público é inseguro, violento e depredado. Neste sentido, a paisagem urbana das praças conforme nos apresenta Milton Santos, por meio das estratégias de poderes operadas pelo estado brasileiro, se adapta a essa nova situação. No entanto, a praça, este corpo afetado, conduz também a novos modos de ser e estar na sociedade brasileira ao relacionar outros hábitos de consumo e outros usos deste espaço público pelo viés da racionalidade neoliberal na manutenção de poderes derivada do processo de urbanização.

Por meio da disposição socioeconômica apresentada pelo sistema neoliberal, movimentos afetivos se estabelecem nas relações entre o corpo-praça-sociedade no espaço urbano. Assim, buscamos elaborar uma cartografia social como metodologia de pesquisa para esta reflexão fundamentada em conceitos propostos por Deleuze e Guattari no campo político e estético. Ao trazerem o conceito de rizoma atrelado à formação cartográfica, os autores introduzem uma nova perspectiva de agregar o conhecimento, não se restringindo ao modelo cartesiano semelhante a uma árvore. Neste sentido, a cartografia vai além, ao promover uma aliança aos saberes das ciências humanas, permitindo um olhar na história e em suas descontinuidades narrativas na composição do espaço rizomático através da abordagem realizada pelo pesquisador/pesquisadora que se torna cartógrafo/cartógrafa. Estamos diante de um mapa aberto com múltiplas entradas 
(econômica, política, social) que se unem às maneiras de articulação da praça como dispositivo e se torna ferramenta para a metodologia aplicada nesta compreensão - junto com o trabalho de campo.

Deleuze e Guattari nos propõem:

O mapa é aberto, é conectável em todas as suas dimensões, desmontável, reversível, suscetível de receber modificações constantemente. Ele pode ser rasgado, revertido, adaptar-se a montagens de qualquer natureza, ser preparado por um indivíduo, um grupo, uma formação social. (Deleuze \& Guattari, 1995: 21)

Utilizando-se destes conceitos filosóficos problematizamos as fraturas espaciais geradas por esta estratégia de poder operante no espaço urbano constituído pela racionalidade neoliberal. O intuito é estabelecer uma reflexão sobre a perda da relação humana com o espaço urbano. Voltemos, então, nossa análise para duas praças na região do Distrito Federal: a Praça do Povo, localizada no Plano Piloto e a Praça do Cidadão, na região da cidade-satélite de Ceilândia. Buscaremos compreender as camadas de subjetividades emergidas deste dispositivo pelos afetos através de uma ressignificação dos espaços urbanos mencionados.

\section{A corporização afetiva das praças pelo sensível em tempos neoliberais}

A cidade de Brasília é conhecida mundialmente por sua arquitetura moderna fundamentada pelos princípios de Le Corbusier, que trouxe elementos funcionalistas para o planejamento urbano brasileiro. Motivado pela transferência da capital do Rio de Janeiro para a região central, o presidente Juscelino Kubitschek (1956-1961) aplicou o seu Plano de Metas, cujo lema era "50 anos de progresso em 5", com o intuito de promover a industrialização e o desenvolvimento do país. Criou-se, assim, um imaginário de progresso e de utopia nesta região localizada no Planalto Central por meio da inauguração da cidade planejada nos anos de 1960.

No final da década de 1950, um fluxo populacional se intensificou, seguindo em direção à construção da nova capital, motivado pelo sonho de ter um emprego e melhores condições para se viver. Esses se tornaram operários da construção de Brasília, mas não podiam habitá-la. Assim surgem os primeiros assentamentos de operários e o deslocamento desta parte da população para áreas mais afastadas da zona central, com a criação das cidades satélites. Essas regiões são denominadas como "cidadesdormitórios", sem infra-estrutura de serviços e opções de lazer, restritas ao centro de 
Brasília. É fundamental ressaltarmos que o Plano Diretor do Plano Piloto, concebido pelo arquiteto Lúcio Costa, promovia uma setorização da cidade de Brasília em áreas residenciais e comerciais com suas respectivas funções. No entanto, o discurso associado à cidade planejada gerou embates já em sua construção, provocando uma segregação social latente até hoje.

A transformação da paisagem urbana no Brasil e, consequentemente também em Brasília, por meio do processo de espetacularização imobiliária, gerou um aumento de construções em ambientes privados a partir dos anos de 1990. Observamos o surgimento de espaços como shopping centers e condomínios, levando a um esvaziamento do uso do espaço público das cidades. As formas de experienciá-lo são alteradas com a presença de muros e cercas, ocasionando um movimento coletivo de pessoas restrito ao espaço privado e de maneira individual. Vale ressaltarmos que os conceitos de segurança e vigilância também são apropriados nesta formação discursiva em justificativa aos modos operantes do sistema neoliberal e configuram uma nova relação com o espaço em transformação.

Uma corpografia urbana é um tipo de cartografia realizada pelo e no corpo, ou seja, a memória urbana inscrita no corpo, o registro de sua experiência da cidade, uma espécie de grafia urbana, da própria cidade vivida, que fica inscrita mas também configura o corpo de quem experimenta. (Jacques, 2008: s/p)

Nesta perspectiva de experienciar o espaço público, que é perdida com o processo de privatização dos lugares, estabelece-se um rompimento corporal referente às trocas entre as pessoas e as praças. Estas se tornam simples cenários e diminuem a sua capacidade de promover o encontro e, consequentemente, uma corpografia urbana. A pesquisadora Paola Berenstein Jacques (2008) considera essa perda como forma de resistência ao conceito de corpografia urbana. Tais características podem ser pensadas para o caso das praças e se tornam uma crítica a esse lugar afetado por mudanças econômicas e sociais.

Paralelamente, as fraturas ocasionadas pela paisagem urbana nas praças públicas produzem subjetividades que são resultados de processos históricos e sociais que se dão ao longo da urbanização das cidades. Neste fluxo, os acessos a opções de lazer se restringem a uma parcela da população e privam outras da partilha do sensível ${ }^{5}$. A força

\footnotetext{
${ }^{5} \mathrm{O}$ autor Jacques Rancière nos apresenta o conceito da partilha do sensível nesta relação com o comum a qual estamos perdendo: "uma partilha do sensível é, portanto, o modo como se determina no sensível a relação entre um conjunto comum partilhado e divisão de partes exclusivas. (Rancière, 2009: 7).
} 
operada pelo sistema neoliberal gera a perda do uso comum, da qual problematizamos, a partir da filosofia spinozista, a construção do lugar de encontro. Em concordância a este modelo, o processo discursivo se baseia na produtividade, eficiência e utilidade das coisas no âmbito privado, descaracterizando o uso do espaço público e tornando-o ineficiente. Além disso, tal mecanismo revela ainda mais as disparidades sociais. Diante desta perspectiva e contrastes gerados pelo neoliberalismo nos indagamos: quem pode ocupar esses espaços?

O movimento de fora para dentro com relação ao uso do espaço urbano pelas pessoas se une ao imaginário criado pela racionalidade neoliberal e não está, portanto, desvinculado do contexto histórico e econômico de quem o vivencia. A arquitetura se modifica de acordo com as alterações afetivas contemporâneas, muito pautadas pelo medo e pela violência, estabelecendo um discurso específico que é, por sua vez, resultado das relações entre a mente e o corpo no espaço urbano, conforme discorremos anteriormente. As circunstâncias de abandono e sucateamento das praças públicas contrastam com os lugares iluminados, confortáveis e seguros, associados ao imaginário dos ambientes privados. Como trazer de volta a sensação de pertencimento a todos e todas em um espaço público? Como sair destas zonas padronizadas apresentadas por estes espaços privados e compor uma produção de espaço singular das praças públicas?

Henri Lefebvre nos diz:

Resta elucidar a relação entre esse espaço fragmentado e as múltiplas redes que combatem a fragmentação e restabelecem, sendo uma unidade racional, ao menos a homogeneidade. Através e contra a hierarquização, não pode romper, aqui ou ali, arquitetural ou urbanisticamente, "algo" que sai do modo de produção que existe, que nasce de suas contradições, revelando-as e não as cobrindo com um véu? (Lefebvre, 2006: 15)

A partir destas inquietações e das trocas entre os saberes científicos aliados a esta questão das praças públicas, questionamos a perspectiva de produção do espaço urbano contemporâneo. Será que conseguiremos compartilhar as experiências pelo sensível e resgatar o afeto de pertencimento perdido com as praças? Neste movimento constante, a história compõe novos territórios a se constituírem com relação ao dispositivo das praças, estabelecendo cartografias sociais de resistência à organização esperada para determinados espaços: “desemaranhar as linhas de um dispositivo é, em cada caso, traçar um mapa, cartografar, percorrer terras desconhecidas." (Deleuze, 2020: s/p). Sendo assim, as rupturas construídas neste processo de urbanização apresentam uma subversão ao espaço ao estabelecer novos sentidos para as relações humanas que aí se desenrolam. 
Praça do Povo e a Praça do Cidadão

Observamos os princípios funcionalistas adotados pela arquitetura moderna através da concepção da área central de Brasília, denominada Setor Comercial Sul. Os prédios apresentam um padrão em sua construção e se destinam à prestação de serviços públicos ou privados para a população. A região abarca um fluxo intenso de pessoas que trabalham ou acessam o local em decorrência das atividades fornecidas. O movimento que pulsa em horários comerciais durante a semana se distingue daquele do período da noite e dos finais de semana. O esvaziamento e descuido desta área se tornam mais evidentes diante do modo de gestão neoliberal e convergem para a construção de um afeto associado ao não-pertencimento e medo em relação àquele local.

Em meio às idas e vindas, encontra-se a Praça do Povo no Setor Comercial Sul. As sombras das árvores se mesclam à vegetação alta, folhas secas e lixo espalhado na região. O local destinado ao encontro das pessoas está vazio e sem manutenção. A área perdeu a sua função e reflete posturas incoerentes e descomprometidas do uso do espaço público pelos modos operantes estatais. Nesta perspectiva de resgate e retomada do acesso às praças públicas surgem iniciativas por meio de intervenções artísticas para subverter o espaço urbano e gerar novos afetos pela resistência e a ocupação pela comunidade, procurando ampliar a partilha do sensível naquele espaço destinado a todos e todas. Desta forma, mensagens por estêncil, lambe-lambes e grafites aparecem com o intuito de promover uma nova imagem e gerar uma reflexão política nesta praça por meio da arte. Segundo Nelson Brissac Peixoto (1999), tais intervenções acabam por estabelecer relações outras com a paisagem da cidade, reforçando que o espaço público é, também, o local de transformações políticas e artísticas.

Figura 1: Praça do Povo, Setor Comercial Sul Brasília 


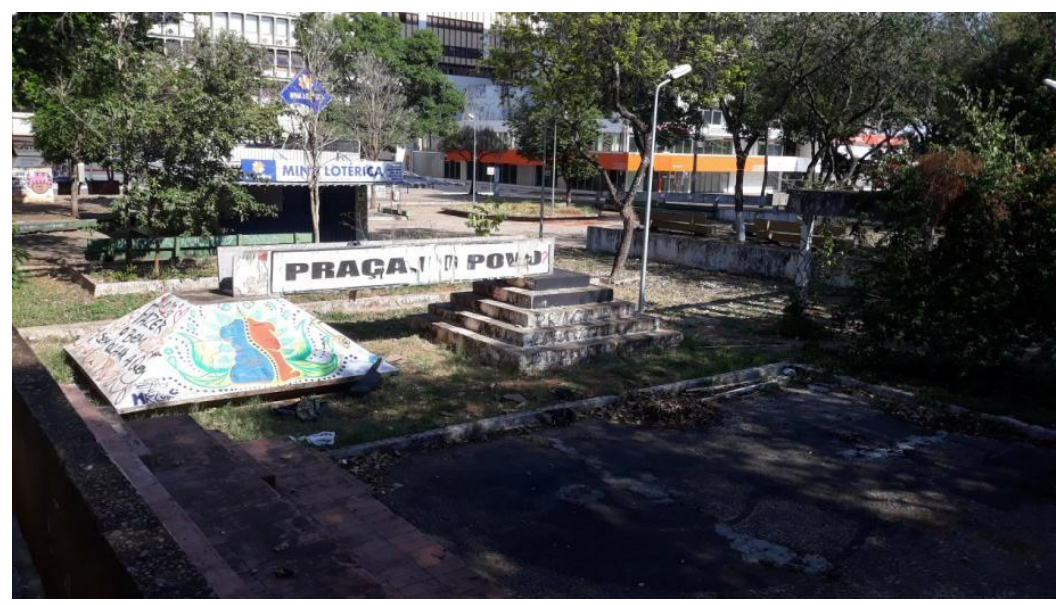

Fonte: Fotografia de Lorena Figueiredo

A tipografia em bold que podemos ver na figura 1 dá visibilidade ao nome da praça e procura resgatar o significado de pertencimento de quem é esse lugar no centro da cidade. Ao pensar nas características apresentadas no design urbano, o autor Kevin Lynch em seu livro A imagem da cidade considera a categoria nome e significados como um elemento para aumentar a imagem deste elemento, no caso, desta praça, por exemplo. Ele afirma:

Significados e associações, sejam sociais, históricos, funcionais, econômicos ou individuais, constituem todo um domínio para além das qualidades físicas que nos interessam aqui. Reforçam as sugestões de identidade ou estrutura que podem estar latentes na própria forma física. (Lynch, 2011: 120)

Quando observamos a intervenção artística feita por uma colagem em lambelambe ao reforçar o nome da Praça do Povo enuncia-se um paradoxo entre o fazer artístico e a política presente naquele espaço público. Portanto, a visibilidade do texto pela arte de rua realizada permite revelar a indagação sobre quem são as pessoas destinadas a ocupar esse espaço e quais invisibilidades são geradas no regime de dissenso do suposto uso comum.

Arte e política têm a ver uma com a outra como formas de dissenso, operações de reconfiguração de experiência comum do sensível. Há uma estética da política no sentido de que os atos de subjetivação política redefinem o que é visível, o que se pode dizer dele e que sujeitos são capazes de fazê-lo. Há uma política da estética no sentido de que as novas formas de circulação da palavra, de exposição do visível e de produção dos afetos determinam capacidades novas, em ruptura com a antiga configuração do possível. (Rancière, 2012: 63)

Figura 2: Lambe-Lambes na Praça do Povo 


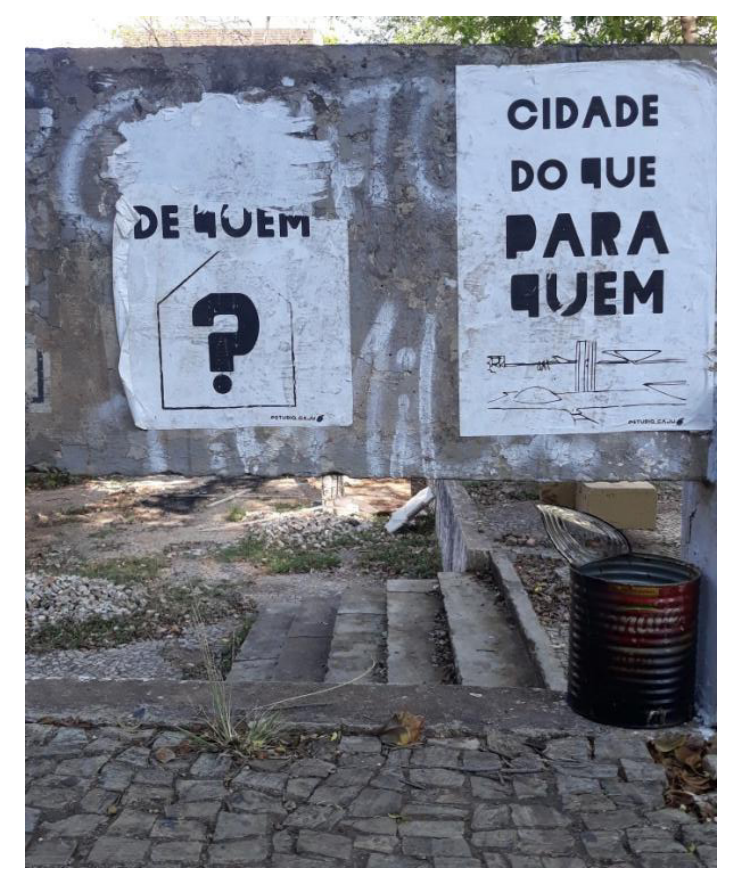

Fonte: Fotografia de Lorena Figueiredo

A construção retangular da praça, com escadas que funcionam como bancos e zonas de acesso ao espaço central, apresenta-se com o concreto desgastado. O resultado é um local com várias estruturas rompidas pelo tempo e sem manutenção. A descontinuidade arquitetônica, consequência da ausência de preservação deste espaço público, realça um pedido de ajuda presente em dois lambes colado pelo Studio Caju ${ }^{6} \mathrm{em}$ suas estruturas laterais. Os dizeres De quem? e Cidade do que para quem presentes na Figura 2 problematizam o imaginário utópico de cidade do futuro consolidado desde a construção de Brasília na constituição da área referente ao Plano Piloto.

Em entrevista concedida para este artigo, a estudante de arquitetura Jasmine Benavenuto e criadora do Studio Caju nos apresenta uma reflexão fundamentada em uma pesquisa de campo de quase um ano sobre a Praça do Povo para o seu trabalho de conclusão de curso no Centro Universitário de Brasília (UNICEUB). A pesquisadora se sentiu motivada a criar uma proposta além de um objeto arquitetônico e passou a analisar o trânsito de pedestres, automóveis, transporte público na região e pessoas em situação de rua que ali habitavam. Cada detalhe na rotina convergia com a frase do autor Nelson Saldanha que a instigou a iniciar o estudo: "a praça é, em certo sentido, a essência da

\footnotetext{
${ }^{6}$ Estúdio de design de interiores e ilustração local, com foco em estética brasileira e brasiliense. Disponível em: https://jasminebenavenuto.wixsite.com/studiocaju Acesso em 16. out. 2020
} 
cidade". Os imaginários da cidade planejada nesta área central se chocavam com as ações de arquitetos, urbanistas e gestões de governadores.

Nesta perspectiva de indagar sobre o papel das pessoas e o seu poder de transformação ao se apoderar do espaço urbano, a escolha de usar os lambe-lambes como intervenção artística na Praça do Povo permitiu contestar formas de pensamentos vigentes instaurados durante anos pelas instituições de poderes de forma descentralizada e direta pela arte de rua. Benavenuto considera que embora o trabalho tenha sido realizado de maneira individual, a ação é coletiva devido às percepções absorvidas a partir de suas intervenções pelas pessoas que utilizam o Setor Comercial Sul. Com esse desvelar de camadas do espaço urbano, vão emergindo na praça um outro olhar para dialogar sobre atualidade e as relações humanas. Sendo assim, subversões estético-políticas realizadas por meio das intervenções artísticas ampliam uma reflexão para a potencial mudança, mesmo que gradual.

Retomando as configurações do plano urbanístico da nova capital, a cidadesatélite de Ceilândia surge como uma região periférica do Plano Piloto. Desde a sua constituição, nos anos de 1970, a sigla CEI (Centro de Erradicação de Invasões) representou a segregação espacial e social associada ao imaginário da construção de Brasília. O processo rápido de urbanização para o assentamento dos operários que vieram para a construção também apresentou a construção de uma cidade sem infraestrutura de serviços e lazer. No entanto, as praças nas regiões das cidades satélites retomam a sua concepção inicial de lugar de encontro, mesmo diante da falta de manutenção e cuidado com o espaço público aliado ao discurso de medo e violência agregado às áreas periféricas.

Consideramos a Praça do Cidadão, localizada na cidade-satélite de Ceilândia, nesta reflexão afetiva e de resgate do uso do espaço público. Já o nome do lugar permite reforçar a identidade e a vocação para constituição de um espaço destinado à partilha do sensível. Em termos arquitetônicos, a área apresenta uma quadra poliesportiva, um coreto, um espaço de arte e cultura com atividades destinadas à formação de jovens e adultos ${ }^{7}$, árvores e bancos ao redor, além da presença de uma Agência do Trabalhador, que concentra serviços públicos, facilitando o acesso dos moradores às vagas ofertadas para

\footnotetext{
${ }^{7}$ Este grupo é constituído pelo Jovem de Expressão, um programa social para jovens entre 18 e 29 anos que visa promover, através da metodologia de arte-educação e empreendedorismo cultural, a prática de não violência e saúde nesta região. Mais informações sobre o projeto disponível em: https://jovemdeexpressao.com.br/ . Acesso em: 04. fev. 2021
} 
alguma oportunidade de emprego. O fluxo de pessoas na região é intenso em distintos horários e diminui à noite, também devido às estruturas de iluminação e segurança precárias.

Figura 3: Praça do Cidadão - parte localizada em frente ao Jovem de Expressão

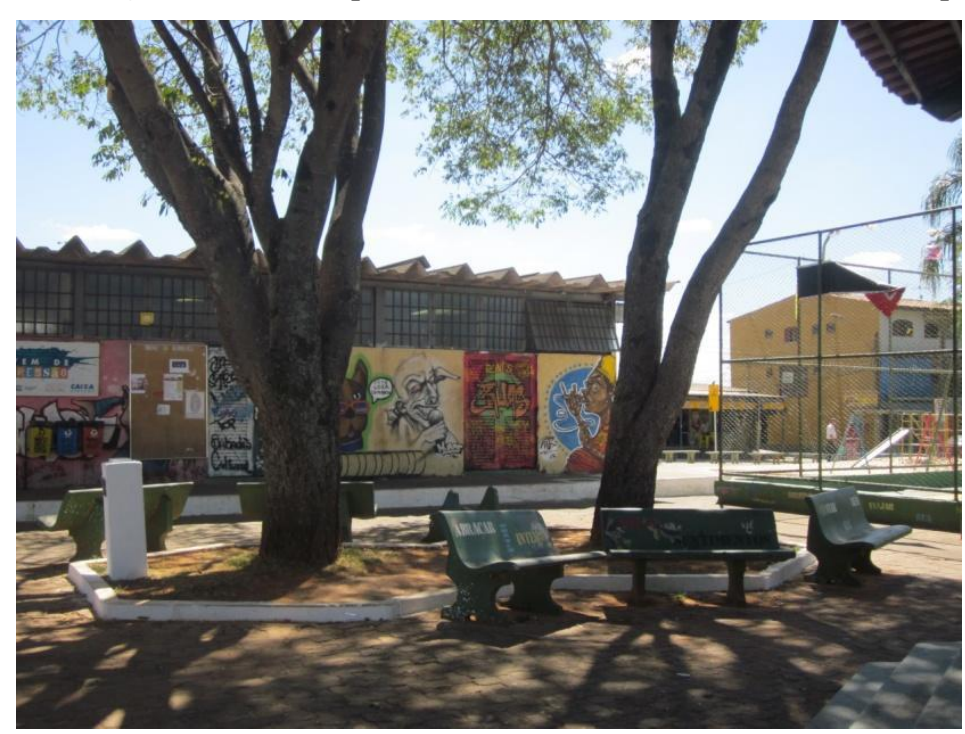

Fonte: Fotografia por Lorena Figueiredo

$\mathrm{Na}$ busca de pertencimento e uso do espaço urbano pelos moradores, o Coletivo Mapa Gentil ${ }^{8}$ - Plante Gentileza realizou intervenções artísticas com placas personalizadas e mensagens em estêncil na praça do Cidadão em conjunto com os jovens desta cidade. O coletivo, em parceria com o projeto Jovem de Expressão, toma um local abandonado e esquecido pela gestão pública, o revitaliza e ressignifica ao expressar um anseio da sua população local. A artista e realizadora do projeto, Janaína André ${ }^{9}$, em entrevista para o artigo, comenta sobre a parceria com a população local e o intercâmbio de ações entre os artistas do Plano Piloto com os artistas de Ceilândia. A urgência em tomar o espaço urbano pela arte durante o processo de criação reverbera algo para além de simplesmente chamar a atenção, mas também, trazer soluções colaborativas ao local. Sendo assim, a técnica do estêncil foi muito utilizada nas ações.

As autoras Joana Schneider e Helene Sacco, no artigo "Estêncil e Serigrafia: os usos tradicionais e artísticos da técnica de molde vazado" ressaltam a concepção da

\footnotetext{
${ }^{8}$ Informações sobre o Coletivo Mapa Gentil disponível em: https://mapagentil.com.br/. Acesso em: 09. out. 2020.

9 Página da artista Janaína André disponível em: https:/www.instagram.com/janainaandre/ . Acesso em: 04.fev. 2021.
} 
técnica do estêncil criada por japoneses e chineses entre 500 a 1500 a.C. De acordo com elas,

No final do século XIX, surge na França o porchoir (molde vazado), no entanto a técnica só foi patenteada em 1907, na Inglaterra por Samuel Simon e o termo se tornou mais conhecido em inglês, estêncil, sendo amplamente usado no século XX. (Scheneider; Sacco, 2019: 4).

Retornando às ações do Mapa Gentil, Janaína André comenta que a técnica do estêncil é pouco usada pelos artistas do Distrito Federal, mas de fácil aplicação e muito potente, estimulando a produção no e, consequentemente, do espaço.

Para a artista Janaina André, aumentar o espaço de expressão da comunidade e a ocupação do espaço público devem convergir como uma extensão da nossa casa e nos diz: " a arte é ativismo em qualquer sistema, mas arte urbana em especial tem ainda um caráter mais subversivo e questionador, pois é um espaço em evidência, um espaço do povo e para o povo manifestar suas ideias de forma pura, potente e crítica". Neste movimento criado pela arte de rua se abre uma nova perspectiva de perceber e estar no mundo, emergindo visibilidades estéticas ao espaço urbano.

A cidade e a arte de rua se conectam, então, pela criação de um espaço de resistência e de alteridade, pois as atividades humanas se restringem ao individual e perdem a capacidade de troca com o coletivo, na contemporaneidade. Ao tomarmos o caráter político presente na Estética, este tipo de arte compõe uma relação de pertencimento com o lugar ao reconfigurar o encontro com a rua, gerando novas formas de pensamento. Sabemos que muitos artistas gostariam de ocupar os ambientes destinados à arte com galerias e museus, porém estar na rua, neste momento, é gerar novas relações e afetos entre o espaço e a cultura que estão sendo rompidos. Portanto, ao partirmos do conceito da partilha do sensível, a busca é reivindicar uma prática de alteridade e reorganizar as relações socioculturais entre indivíduos e cidade, transformando a paisagem urbana em uma galeria aberta.

\footnotetext{
Denomino partilha do sensível o sistema de evidências sensíveis que revela, ao mesmo tempo, a existência de um comum e dos recortes que nele definem lugares e partes respectivas. Uma partilha do sensível fixa portanto, ao mesmo tempo, um comum partilhado e partes exclusivas. Essa repartição das partes e dos lugares se funda numa partilha de espaços, tempos e tipos de atividade que determina propriamente a maneira como um comum se presta à participação e como uns e outros tomam parte nessa partilha. (Rancière, 2009: 15)
}

Assim, ressaltamos, nesta reflexão, a concepção de uma política da arte pelo sensível desenvolvida nesta praça pelo coletivo e os moradores da região, nos moldes da 
concepção de Jacques Rancière ${ }^{10}$. Ele observa um aspecto situacionista ao reivindicar 0 uso do espaço público e podemos aplicar seu pensamento no movimento de revolução (e até mesmo de subversão) do espaço urbano da cidade satélite de Ceilândia de maneira afetiva, como veremos a seguir.

Os situacionistas chegaram a uma convicção exatamente contrária à dos arquitetos modernos. Enquanto os modernos acreditavam, num determinado momento, que a arquitetura e o urbanismo poderiam mudar a sociedade, os situacionistas estavam convictos de que a própria sociedade deveria mudar a arquitetura e o urbanismo [...]os situacionistas, ao contrário, queriam provocar a revolução e pretendiam usar a arquitetura e o ambiente urbano em geral para induzir à participação, para contribuir nessa revolução de vida cotidiana contra a alienação e passividade da sociedade. (Jacques, 2008: 20-21)

A nomenclatura "Praça do Cidadão" emerge das inúmeras invisibilidades provenientes do processo de segregação constituído pela urbanização da cidade de Ceilândia. O campo de disputa criado pela arquitetura modernista, fundado no imaginário utópico de Brasília, bem como o modo de controle social, não se mantiveram no desenvolvimento das cidades-satélites. Tantas camadas entrelaçadas por jogos de poderes, que se intensificam com um discurso associado à racionalidade neoliberal e provocam uma fratura profunda na compreensão desses territórios. Esse movimento pelo coletivo artístico e pela população, ao subverter as hierarquias das instituições, permite que as praças atuem como um dispositivo de resistência a partir do momento da tomada de consciência do uso do espaço público. As potências afetivas se tornaram variáveis com as intervenções artísticas ao criarem uma paisagem alegre e de pertencimento para toda a população local por meio de novas narrativas de subjetividades, como podemos observar nas figuras 4 e figura 5 .

Figura 4: Placa - Arte urbana na Praça do Cidadão

\footnotetext{
${ }^{10} \mathrm{Um}$ dos fundadores da Internacional Situacionista nos apresenta a ideia central presente neste movimento no artigo Report on the Construction of Situations and on the International Situationist Tendency 's Conditions of Organization and Action de 1957. Segundo Debord, "nossa ideia central é a construção de situações, isto é, construção concreta de ambiências momentâneas da vida, e sua transformação em sua qualidade passional [...] O ambiente material da vida e dos comportamentos que dão origem e transformam radicamente". (Debord, 1957 - $\quad$ Tradução nossa) Disponível em: https://www.cddc.vt.edu/sionline/si/report.html . Acesso em 04. fev. 2021
} 


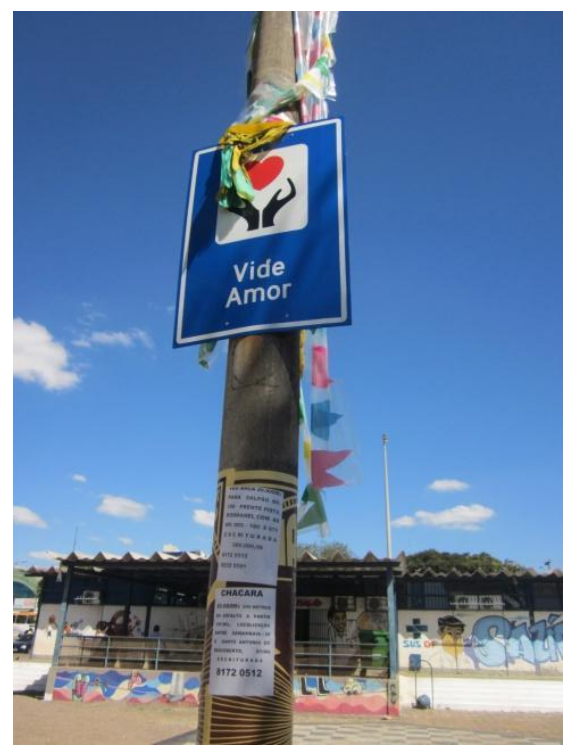

Fonte: Fotografia de Lorena Figueiredo

Figura 5: Placa - Estêncil na Praça do Cidadão

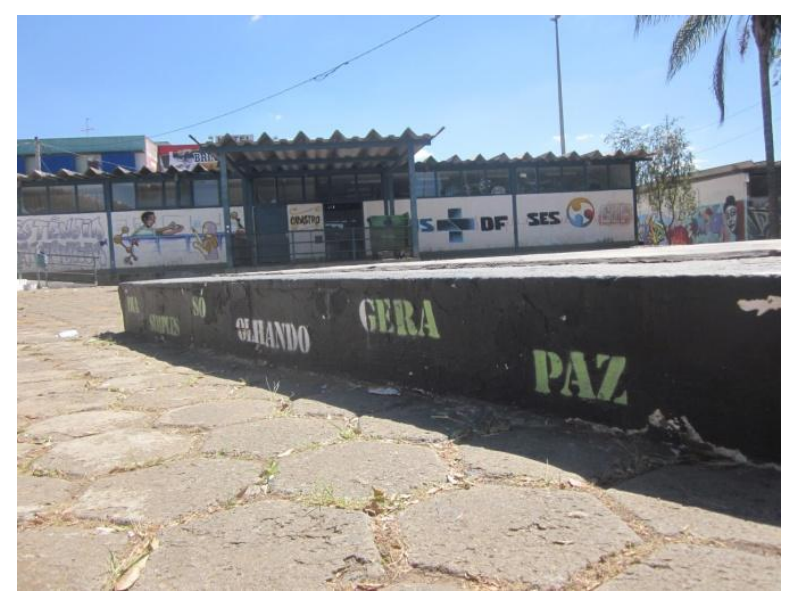

Fonte: Fotografia de Lorena Figueiredo

\section{Considerações finais}

O artigo buscou refletir sobre a situação de duas praças localizadas em regiões distintas do Distrito Federal. Propusemos, aqui, um resgate de significados e problematizações que partiam do diálogo com os conceitos de afeto e de corpo afetado, da filosofia spinozista. Tendo em vista a cartografia social como método de pesquisa, uma rede de saberes e conhecimentos começaram a se estabelecer com conexões a partir das subjetividades percebidas neste mapa aberto, criado pelos imaginários, pelos discursos e pelas rupturas do processo de urbanização de Brasília e das cidades-satélites vigente na sociedade que a habita. 
A investigação se propôs a realizar indagações sobre o abandono do espaço público, especificamente das praças, em decorrência da falta de ações governamentais, dos processos de urbanização das cidades e da implantação de uma racionalidade neoliberal que atravessa os corpos - tanto fisicamente quanto mentalmente - ao instaurar um modelo de gestão econômica e política. A partir desses fatores externos, como observados pela historiografia brasileira e brasiliense, percebemos uma variação na potência de agir sobre corpos, neste caso, as praças. O discurso do medo, da violência e a insegurança se tornam sinônimos para as pessoas deixarem de usufruir dos espaços públicos. É importante ressaltar que no desvelar de camadas imaginárias, as praças atuam como uma espécie de dispositivo num emaranhado de forças e poderes presentes no sistema vigente e sofrem com a postura adotada pelo Estado.

Como uma tentativa de resgate do uso do espaço público das praças pelos afetos, intervenções artísticas realizadas pelo Studio Caju na Praça do Povo, no Setor Comercial Sul, e pelo Coletivo Mapa Gentil, na Praça do Cidadão, região da cidade-satélite da Ceilândia, pudemos indagar sobre a partilha do sensível e os usos compartilhados da cidade por quem a habita. Ao trazermos o retorno das pessoas às praças através das intervenções artísticas, tal como propunham os situacionistas, novas maneiras de subversão do espaço urbano são geradas. Neste movimento de agregar a arte de rua e a comunidade observamos um novo olhar ao espaço urbano, que se estabelece por mensagens - seja através de lambe-lambes, estêncil, placas ou grafites.

Em suma, a proposta de intervenções artísticas no espaço das praças se fundamenta na busca pelo resgate e ocupação dos espaços públicos. A ideia é propiciar o encontro, retomar o sentimento de pertencimento e do comum a todos e todas, permitindo maneiras de experimentar a cidade. Em meio ao emaranhado de poderes que atuam nesta racionalidade neoliberal, as estratégias artísticas de resistência política parecem um desafio complexo, num primeiro olhar. Contudo, é possível, a partir da tomada de consciência em comunidade e ações contínuas para a compreensão e ressignificação, que o espaço urbano das praças volte a servir à sua vocação inicial, ou seja, que volte a ser um espaço público de convívio democrático e coletivo.

\section{REFERÊNCIAS}


COLETIVO MAPA GENTIL. Disponível em: https://mapagentil.com.br/. Acesso em: 09. out. 2020.

DARDOT, Pierre; LAVAL, Christian. A nova razão do mundo: ensaio sobre a sociedade neoliberal. São Paulo: Boitempo, 2016.

DEBORD, Guy. 1957. In: Internationale Situationniste. Vol. 1, 1958. Disponível em: https://www.cddc.vt.edu/sionline/si/report.html Acesso em: em 04. fev. 2021

DELEUZE, Gilles. Foucault. Tradução Claúdia Sant'Anna Martins; revisão da tradução Renato Riberio, São Paulo: Brasiliense, 2005.

DELEUZE, Gilles. $O$ que é um dispositivo? Disponível em: $<$ http://vsites.unb.br/fe/tef/filoesco/foucault/art14.pdf $>$. Acesso em: 30. set. 2020

DELEUZE, Gilles \& GUATTARI, Felix. Mil Platôs: capitalismo e esquizofrenia. Vol.I. São Paulo: Ed.34, 1995.

FERRARA, Lucrécia DAlessio. As mediações da paisagem. v. 29, n. 15, São Paulo: Líbero, 2012, p. 43-50,

GENNARI, Adilson Marques. Globalização, Neoliberalismo e abertura econômica no Brasil nos anos 90. Revista Pesquisa \& Debate, Volume 13, n.1(21), São Paulo, 2002, p. $30-45$.

JACQUES, Paola Berenstein. Corpografias urbanas. Arquitextos, ano 08, n. 093.07, São Paulo: Vitruvius, fev. 2008

LAUANDE JUNIOR, Francisco de Assis. Brasília: a Praça dos Três Poderes. 2008. 178 f. Dissertação (Mestrado em Arquitetura e Urbanismo) - Universidade de Brasília, Brasília, 2008.

LEFEBVRE, Henri. A produção do espaço. Trad. Doralice Barros Pereira e Sérgio Martins (do original: La production de l'espace. 4e éd). Disponível em: https://gpect.files.wordpress.com/2014/06/henri_lefebvre-a-produc3a7c3a3o-doespac3a7o.pdf Acesso em 04.fev.2021.

LYNCH, Kevin. A imagem da cidade. Tradução Jefferson Luiz Camargo. $3^{\text {a }}$ ed. São Paulo: Editora Martins Fontes, 2011.

PEIXOTO, Nelson Brissac. Intervenções Urbanas. Rua, Campinas, Número Especial: 8188, 1999.

PROGRAMA SOCIAL JOVEM DE EXPRESSÃO. Disponível em https://jovemdeexpressao.com.br/ . Acesso em: 04.fev. 2021

RANCIÈRE, Jacques. Partilha do Sensível: estética e política. Tradução de Mônica Costa Net. São Paulo: EXPO experimental org: ED. 34, 2009, 72p 
RANCIÈRE, Jacques. O espectador emancipado. Tradução Ivone C Benedetti. São Paulo: Editora WMF Martins Fontes, 2012.

ROLNIK, Raquel. O que é a cidade. São Paulo: Brasiliense (Coleção Primeiros Passos). Ebook, 2017.

SANTOS, Milton. A natureza do espaço: Técnica e tempo, razão e emoção. 4.ed. São Paulo: Editora da Universidade de São Paulo, 2006.

SANTOS, Milton. Pensando o espaço do homem. 4a ed. São Paulo: HUCITEC, 1997.

SCHNEIDER, Joana; SACCO, Helene Gomes. Estêncil e Serigrafia: os usos tradicionais e artísticos da técnica de molde vazado. Revista Seminário de História da Arte. Volume 01, nº 08, 2019.

SPINOZA, 2009. Ética/Spinoza. Tradução Thomas Tadeu. Belo Horizonte: Autêntica Editora, 2009.

STUDIO CAJU. Disponível em: https://jasminebenavenuto.wixsite.com/studiocaju Acesso em 16. out. 2020

Recebido: 11/02/2021

Aprovado: 02/06/2021 